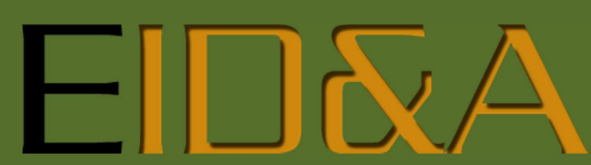

Revista Eletrônica de Estudos Integrados em Discurso e Argumentação

dx.doi.org/10.17648/eidea-16-2219

\title{
ACONTECIMENTO E ARGUMENTAÇÃO NO JOGO POLÍTICO: A VERDADE NA CONSTRUÇÃO DE HERÓIS E VILÕES
}

\author{
Kátia Menezes de Sousa ${ }^{\mathrm{i}}$
}

\begin{abstract}
Resumo: O objetivo deste texto é problematizar alguns enunciados divulgados na mídia brasileira, procurando compreender as relações discursivas que integram as práticas políticas na atualidade e que permitem tornar visível a rede que constrói a necessidade de um conservadorismo de valores morais e sociais na economia e na política. Temos como hipótese que a verdade para a condução do outro e de si mesmo se dá na tensão produzida pelos jogos estratégicos de saber/poder e por acontecimentos discursivos que, em sua emergência, são associados a projetos sociais de uma suposta esquerda, reconfigurando o discurso político, ao ser tratado pela mídia, e justificando formas de resistência marcadas pelo conservadorismo nas propostas e decisões políticas. Adotamos, para isso, algumas noções de Michel Foucault acerca do dispositivo de segurança, da conduta dos homens numa economia de mercado e da condução das almas nas práticas jurídicas e religiosas.
\end{abstract}

Palavras-chave: Discurso político. Mídia. Acontecimento. Argumentação.

Abstract: This article aims to analyze some statements produced in Brazilian media, in order to understand the types of discursives relations which form the political practices in the presente and which reveal the necessities of conservationist, social and moral values in the economy and politics. We take as hypothesis that the argumentative task occurs in the tensions produced in strategic joke of knowledgepower and in discursive event emergence. Also, we agree that the swerve on left in the political discourse can explain the conservationist decisions and proposals, when this discourse circulate in media. We base on Michel Foucault ideas to talk about security device, men conduct in a market economy and conduction of characters in religious and legal practices.

Keywords: Discourse politics. Media. Event. Argumentation.

\footnotetext{
' Docente do Programa de Pós-Graduação em Letras da Universidade Federal de Goiás (UFG), Brasil. E-mail: km-sousa@uol.com.br.
} 
EID\&A - Revista Eletrônica de Estudos Integrados em Discurso e Argumentação, Ilhéus, n. 16 esp. "Discurso e argumentação na política latino-americana, set.2018.

\section{Considerações Iniciais}

Ao falar do eixo metodológico de suas pesquisas até o ano de 1973, em A verdade e as formas jurídicas, Michel Foucault (1996) explica que seu objetivo foi mostrar como as práticas discursivas engendram domínios de saber que fazem aparecer não somente novos objetos, conceitos e técnicas, mas também novas formas de sujeitos e de sujeitos de conhecimento. Esse objetivo o conduziu ao que, conforme assinala o autor, "poderíamos chamar de análise dos discursos" (FOUCAULT, 1996, p. 9), já que, pelos avanços dos estudos do caráter linguístico dos fatos de linguagem, teria chegado o momento de considerar os fatos de discurso como "jogos estratégicos de ação e de reação, de pergunta e de resposta, de dominação e de esquiva, como também de luta" (FOUCAULT, 1996, p. 9). É sob essa concepção de discurso que trabalharemos com a hipótese de que o exercício argumentativo se dá na tensão produzida nesses jogos estratégicos e na emergência do acontecimento discursivo.

Foucault situa o discurso entre a estrutura e o acontecimento pelo fato de ele conter regras da língua e abranger o que é dito, requisitando o estabelecimento de relações. Um acontecimento excede, portanto, à sua discursividade e faz aparecerem diferentes estratos de acontecimentos, dos quais alguns podem ser visíveis e capazes de suscitar outros imperceptíveis para os contemporâneos (FOUCAULT, 2000). Para ilustrar esse caráter de visibilidade e de invisibilidade do acontecimento discursivo, Foucault (2000, p. 292) cita uma pesquisa sobre os modos de alimentação das populações europeias no século XIX, por meio da qual perceberam um crescimento brusco da quantidade de proteínas consumidas, o que constitui um "acontecimento prodigiosamente importante para a história do consumo, da saúde, da longevidade [...] muito mais significativo do que uma mudança de Constituição e do que a passagem de uma monarquia à república".

Com base nesse caminho metodológico, delimitamos, para este trabalho, considerar a argumentação política no Brasil atual tensionada pelos acontecimentos discursivos encenados pelos veículos midiáticos que desenterram camadas mais profundas de acontecimentos que fazem precipitar o retorno de práticas e valores conservadores como forma de conduzir a população. Considerando a noção de acontecimento, olhamos para a atualidade como um presente que não se reduz a um instante pontual, mas que se insere na duração como efetuação do futuro relembrado, sendo a 
EID\&A - Revista Eletrônica de Estudos Integrados em Discurso e Argumentação, Ilhéus, n. 16 esp. "Discurso e argumentação na política latino-americana, set.2018.

história aberta para o campo dos possíveis e para a dimensão do agir (DOSSE, 2013).

Nesse sentido, interrogamos se o acontecimento da suposta tendência mais à esquerda dos programas sociais na configuração do discurso político, ao ser tratado pela mídia, pode explicar o conservadorismo nas propostas e decisões políticas e no comportamento das pessoas, bem como a judicialização da política e a politização da justiça, a culpabilização das políticas sociais do governo na queda do crescimento econômico do país e a recorrência à moral cristã como forma de conduzir os homens às práticas hegemônicas que possam extirpar o medo desencadeado pela resistência à docilização e à normalização dos corpos da população.

Para a problematização das relações entre enunciados que possam apontar as regularidades na possibilidade de retorno do conservadorismo nas formas de fazer a política na atualidade brasileira, percorreremos algumas noções de Michel Foucault (2008a; 2008b; 1996; 2011) acerca do dispositivo de segurança, da conduta dos homens numa economia de mercado, da condução das almas (das condutas, dos comportamentos) nas práticas jurídicas e religiosas, apropriadas pela política e pela mídia, e do discurso político, tensionado pelos discursos de verdade do mercado, do judiciário, da moral cristã e da mídia. São relações em nós, cujas pontas podem se unir ou se separar conforme os acontecimentos que vão reconfigurando o discurso político e as formas de subjetividade que vão sendo fundadas e refundadas por essas relações. Trata-se, ainda, de um jogo, cujas regras formulam a verdade para a definição dos domínios do objeto político, dos tipos de saberes que os envolvem e de suas formas de subjetividade. Nesse jogo em que a argumentação também é da ordem do acontecimento, suas características colocam, em cena, enunciados e funções enunciativas que se deslocam, circulam, conforme o acontecimento que os dispara, em posicionamentos que os colocam ou não como do lado da verdade. Instaura-se, assim, a luta para se ter a verdade em seu poder, para mostrar que a verdade está em um posicionamento e não em outro, e a mídia funciona como testemunha e juíza da verdade e de sua falta. E essa verdade produzida pela força de um acontecimento discursivo sobre outros acaba por construir heróis e vilões, conforme o julgamento da mídia. Mas onde estão os vilões disfarçados de heróis? Como os acontecimentos vão sendo relacionados para produzirem as máscaras e também para disfarçá-las? Quais discursos entram em 
EID\&A - Revista Eletrônica de Estudos Integrados em Discurso e Argumentação, Ilhéus, n. 16 esp. "Discurso e argumentação na política latino-americana, set.2018.

funcionamento para acusar o disfarce de um grupo ou para disfarçar a máscara de outro grupo? Em quais domínios os vilões não precisam de disfarce e por quê?

$\mathrm{Na}$ tentativa de perceber as regularidades que possibilitam a emergência dos saberes e das forças discursivas que resgatam as práticas conservadoras para o domínio político, analisaremos alguns enunciados produzidos na mídia brasileira, procurando separar e colocar em meadas as linhas discursivas que integram as práticas políticas na atualidade brasileira. Trata-se de uma análise sucinta que procura apontar para as rotas de entrada nas relações discursivas tecidas nos enunciados atuais, mas que permitem tornar visível a rede que constrói a necessidade de um conservadorismo de valores morais e sociais na economia e na política.

\section{O dispositivo de segurança e o retorno aos valores conservadores}

No resumo do curso Segurança, Território e População, Foucault (2008a) esclarece que esse curso tratou de um saber político que colocou, no centro de suas preocupações, a noção de população e os mecanismos suscetíveis de garantir sua regulação. Esses mecanismos compõem o dispositivo de segurança que vai ganhando força, no final do século XVIII, a partir do desgaste da disciplina que a tudo pretendia regulamentar. Os dispositivos de segurança tendem a se ampliar, e novos elementos são o tempo todo integrados (produção, psicologia, comportamentos, produtores, compradores, consumidores, o mercado), deixando circuitos cada vez mais amplos se desenvolverem. Trabalham na realidade, fazendo os elementos da realidade atuarem uns em relação aos outros por meio de análises, avaliações, medições. O ponto essencial, conforme Foucault (2008a), é que a segurança compromete todo o pensamento e toda a organização das sociedades políticas modernas, com a ideia de que a política não tem de levar as regras impostas pelo cristianismo, por exemplo, até o comportamento dos homens, mas tem de agir no elemento de uma realidade, sem nunca se descolar do jogo da realidade. Trata-se de um postulado ligado ao princípio do liberalismo, uma tecnologia do poder que Foucault (2008b) vai tratar como uma biopolítica, em que o jogo se dá essencialmente por meio da estratégia de deixar a realidade se desenvolver, seguir seu caminho, de acordo com as leis, princípios e mecanismos que são os da realidade mesma. 
EID\&A - Revista Eletrônica de Estudos Integrados em Discurso e Argumentação, Ilhéus, n. 16 esp. "Discurso e argumentação na política latino-americana, set.2018.

Nesse jogo, a população fica na dependência de toda uma série de variáveis: clima, intensidade do comércio, atividade de circulação das riquezas, leis a que é submetida, hábitos das pessoas, os valores morais ou religiosos que são reconhecidos a este ou aquele tipo de conduta. Foucault (2008a) chama a atenção para a importante mutação que a biopolítica vai impor na organização e na racionalização dos métodos de poder, visto que atuam por cálculos, análises e reflexões, para lidar com a massa de problemas jurídicos, políticos e técnicos que a população levanta, acionando uma série de saberes.

Esses saberes identificam, por meio de cálculos e estimativas, os riscos e perigos a que população pode estar exposta. Conforme Foucault (2008a), caso, risco, perigo, crise são noções importantes que integram o campo de aplicação e as técnicas requeridas pelo dispositivo de segurança. Para ele, "segurança é um conceito não-jurídico que não pode ser reduzido a um Estado autoritário ou Estado de direito, pois ele se refere à vida social" (LEMKE, 2014, p.116), baseando-se em fatos estatísticos, cálculos de risco, previsões de perigos etc., colocando segurança e liberdade, ambas elementos de uma tecnologia de governo, não como princípios opostos, mas como partes constitutivas da governamentalidade liberal. Assim, a insegurança, a instabilidade e a incerteza movimentam, justificam e sustentam o dispositivo de segurança, fazendo com que a liberdade e o medo refiram-se um ao outro.

Na situação política e econômica brasileira atual é fácil constatar as estimativas de riscos constantes, instaurando um medo permanente de fracasso e produzindo formas de desejo e prazer intimamente ligadas ao medo, que realiza uma função moral importante para a visão neoliberal. O medo é a base para constituição do sujeito responsável, confiável e racional, conforme demonstra Lemke (2014), e tem uma função segregadora: ele divide a sociedade em grupos homogêneos, sociais, étnicos, religiosos, econômicos de iguais que são governados pela pressuposição de que ali não há perigo; o perigo está em outro grupo, naquele que parece não ter medo, os bárbaros e perigosos. Aí se forma a intransigência em relação àqueles que podem representar o risco de tornar um grupo, padronizado pelas técnicas do biopoder, suscetível e vulnerável aos riscos e crises. Dessa intransigência com aqueles que não produzem e consomem conforme os padrões neoliberais surgem o ódio e os fundamentos fascistas.

A eleição para presidente do Brasil em 2014 acirrou o sentimento de ódio que já vinha se externando desde 2013 com as manifestações de rua 
EID\&A - Revista Eletrônica de Estudos Integrados em Discurso e Argumentação, Ilhéus, n. 16 esp. "Discurso e argumentação na política latino-americana, set.2018.

encabeçadas, desta vez, pela direita conservadora. Com a reeleição da Presidenta Dilma, a direita liberal, inconformada com os doze anos marcados pela guinada mais à esquerda e com a possibilidade de perder mais uma vez em 2018, encontrou, nos grandes veículos de mídia nacionais e nos candidatos e congressistas liberais, o apoio para produzir fatos e construir uma rede argumentativa que se configurasse como o desvelamento da verdade: a crise econômica e a inevitável recessão. Ao produzir os dados que comprovavam a certeza da crise também produziram os culpados, e esses eram o principal personagem da trama argumentativa: os integrantes do Partido dos Trabalhadores. Esses são colocados como representantes de uma tendência de esquerda corrupta ${ }^{1}$, que impôs às classes mais abastadas do país a obrigação de tirar milhares de brasileiros da situação de pobreza extrema. A construção do acontecimento da corrupção atribuída somente ao governo, agora denominado de esquerda pelos opositores de direita, amparada pela justiça e tornada verdade repetida pelos grandes veículos midiáticos do país, se constitui como o argumento mais forte para o desejo da população de assistir à punição da Presidenta Dilma com a efetivação de seu impeachment.

Diante das denúncias de corrupção do governo, a classe média-alta e mesmo aqueles que alcançaram a classe média durante o governo dito como de esquerda se mostraram como traídos e, por isso, poderiam romper o pacto com aqueles que não pertenciam a seu hegemônico grupo. Juntamente com o discurso da crise econômica, assistimos ao acirramento de práticas de intransigência, ódio e fascismo voltadas para aqueles que defendem a esquerda e para aqueles que não se enquadram nos padrões de normalização da segurança e podem impor a insegurança e o medo àqueles que seguem as regras de produção e consumo do capitalismo. Para a economia neoliberal, as crenças religiosas, as diferenças étnicas, econômicas e sociais pouco importam na gestão de mercado, já que sofrem apropriação e são transformadas em consumidoras, mas, em momentos pontuais, atuam na realidade, e a identificação dos grupos homogêneos dos historicamente privilegiados e prestigiados no Brasil (as ditas "pessoas de bem") com os ideais da direita conservadora foi muito bem-vinda para a configuração do lugar da moral e dos bons costumes, do conservadorismo. E a cisão se dá

\footnotetext{
${ }^{1}$ Pelos objetivos traçados para este trabalho, os enunciados que constituem a Operação Lava-Jato não serão analisados, dada a sua ampla e intricada rede, mas estará implicada nos acontecimentos que reafirmam o conservadorismo.
} 
EID\&A - Revista Eletrônica de Estudos Integrados em Discurso e Argumentação, Ilhéus, n. 16 esp. "Discurso e argumentação na política latino-americana, set.2018.

recolocando as subjetividades e os seus personagens para atuarem na argumentação.

Nesse cenário, a atuação da mídia contrária aos gastos com programas sociais e com o objetivo de disseminar uma imagem negativa do governo do Partido dos Trabalhadores foi decisiva na instauração de um clima de insegurança e medo na população de "cidadãos de bem". Como o dispositivo de segurança está, conforme Foucault (2008a), sempre aberto para atender as emergências produzidas por sua própria atuação, o perigo visado dessa vez foi representado pelas políticas sociais do governo que comprometiam os investimentos para o crescimento econômico do país. Jornalistas e analistas de economia e política afirmavam, via imprensa, a necessidade de o governo economizar e, ao mesmo tempo, outras mídias, principalmente as digitais, por meio de redes sociais, divulgavam opiniões preconceituosas acerca dos programas sociais do governo e boatos sobre a vida de ostentação do expresidente da República, Luiz Inácio Lula da Silva, também do Partido dos Trabalhadores. A constante comprovação da crise pela mídia tradicional e as opiniões conservadoras e os boatos produziram crenças e ódio não só em relação ao Partido dos Trabalhadores, mas também em relação às minorias formadas por pobres, negros, índios, presidiários, a todos aqueles que, inseridos num modelo econômico neoliberal, segundo Foucault (2008b), de oferta-procura, de investimento-custo-lucro, devem ser colocados num modelo desdobrado do econômico e que se estende a outros modelos, o das relações sociais, da existência, do tempo, do futuro, do seu grupo, da sua família.

As análises neoliberais acabam por constituir uma grade econômica que "deve permitir testar a ação governamental, aferir sua validade, deve permitir objetar à atividade do poder público seus abusos, seus excessos, suas inutilidades, seus gastos pletóricos" (FOUCAULT, 2008b, p. 337-338). Ao serem popularizadas pela mídia, as ações sociais contrárias à grade econômica, mesmo que a maioria da população pouco compreenda a respeito de economia ou de neoliberalismo, configuram-se como as vilãs na crise econômica. A mídia compactuou, no cenário brasileiro, com o mercado em sua forma de se comportar como uma ferramenta de discriminação, aferindo em termos de custo e benefício as atividades públicas, mesmo se tratando de grandes programas sociais, fazendo-os passar, conforme Foucault (2008b, p. 339) “por uma espécie de tribunal econômico”, por “uma espécie de filtragem 
EID\&A - Revista Eletrônica de Estudos Integrados em Discurso e Argumentação, Ilhéus, n. 16 esp. "Discurso e argumentação na política latino-americana, set.2018.

de todo enunciado, qualquer que seja ele em termos de contradição, de falta de consistência, de falta de sentido" em relação à grade que afere a ação do governo em termos estritamente de economia e de mercado.

Foucault (2008b), ao explicar esse tribunal econômico, propõe uma analogia com a visão positivista de linguagem que impôs uma filtragem, uma higienização da linguagem cotidiana para adequá-la a uma grade de inteligibilidade. Também, ele demonstra, exemplificando, como a forma econômica do mercado é generalizada em todo o corpo social, funcionando como princípio de decifração das relações sociais e dos comportamentos individuais. Nessa generalização, além da filtragem das ações e discursos, também é colocada para a sociedade a grade para a constituição, o crescimento, a acumulação e melhoria do capital humano, tanto em seus elementos inatos, com a utilização da genética, quanto em seus elementos adquiridos, por meio do investimento educacional e profissional. Assim, o modelo social serve de suporte para a reconstituição dos valores morais, que se baseiam na ideia de indivíduo como um capital humano na medida em que, justamente, a competência-máquina de que ele é renda não pode ser dissociada do indivíduo humano que é seu portador.

Pensar nessas questões relativas ao tribunal econômico e à melhoria do capital humano para analisar o retorno a valores morais conservadores no momento em que a certeza na existência da crise econômica no Brasil e de seus efeitos devastadores é produzida pela oposição política ao governo, juntamente com as grandes empresas e instituições financeiras, com o trabalho insistente da mídia, funcionando como um tribunal, torna possível considerar que essas questões servem de grade argumentativa na defesa da relação entre renda elevada e capital humano elevado, estabelecendo quais são os indivíduos de risco e os tipos de risco que eles representam para aqueles cujo capital humano tenha importância para a economia do país. Nesse sentido, os considerados indivíduos de risco constituem um elemento de insegurança, de causa do medo e de motivo para se buscar a segurança a qualquer preço, mesmo que este preço seja sua exclusão ou anulação social ou até sua retirada do plano da visibilidade.

\section{Economia de mercado $\mathrm{X}$ intervenções sociais}

Como a grande mídia determina os papéis das personagens conforme interesses políticos e econômicos, neste duelo entre esquerda e direita, pelo 
EID\&A - Revista Eletrônica de Estudos Integrados em Discurso e Argumentação, Ilhéus, n. 16 esp. "Discurso e argumentação na política latino-americana, set.2018.

menos em termos discursivos, heróis justiceiros e vilões bandidos ocupam as cenas do jornalismo impresso e televiso progressivamente e continuamente com ações coerentes a seus papéis de forma tal que não é mais preciso atrelar um dado econômico ou uma decifração perspicaz de um crime aos seus respectivos personagens, pois, pela repetição, o público já faz isso automaticamente. As personagens de esquerda viraram bandidos e as da direita, os justiceiros reveladores da verdade, atuando juntamente com a justiça e a mídia. Os dados da economia, como por exemplo, a queda de 3,8\% no $\mathrm{PIB}^{2}$, tema de matéria do telejornal Hoje da Rede Globo do dia 03/03/2016, atestam a culpa do governo na entrada do país em recessão, o que é feito por meio de consultas a economistas e pessoas comuns que perderam seus empregos por motivos de enxugamento de despesas da empresa.

Os resultados da economia brasileira de 2015 precisam ser relacionados à construção da crise econômica que se iniciou em 2014, no período da campanha eleitoral, quando a oposição de direita já falava em recuo do crescimento econômico, avanço do desemprego e até de recessão econômica, para comprovar a incompetência da Presidenta Dilma e do governo do PT. A crise antecipada pela direita e pela mídia durante 2014 e 2015 produziu o medo, a incerteza e a insegurança, fazendo com que as pessoas deixassem de consumir, com que o enxugamento de pessoal nas empresas e indústrias fosse incentivado pela possibilidade de crise, gerando, assim, a retração do comércio e a recessão.

Após toda a explicação acerca da queda de investimentos e consumo, a matéria do Jornal Hoje passa ao cenário político dando voz a governistas, que se mostram otimistas com futuro econômico pelas medidas que estão sendo tomadas, e a opositores liberais que não perdem tempo e culpam o governo eleito, tentando de todas as formas ampliar a rejeição à presidência e seu partido, como forma de ainda tomar o governo pela criminalização da Presidenta. A insistência na incompetência da Presidenta parece funcionar como uma forma de se ter o apoio e a pressão das manifestações populares sobre o Supremo Tribunal Federal. A matéria mais uma vez lembra que o governo gasta muito, não faz a "tarefa de casa", ou seja não economiza. Desde a campanha que, em debates, a oposição cobra do governo o alto custo

2 Disponível em: http://g1.globo.com/jornal-hoje/noticia/2016/03/pib-brasileiro-tem-queda-de38.html 
EID\&A - Revista Eletrônica de Estudos Integrados em Discurso e Argumentação, Ilhéus, n. 16 esp. "Discurso e argumentação na política latino-americana, set.2018.

dos programas sociais e o pouco investimento nos setores da economia de mercado.

Com a produção discursiva da crise e a certeza da culpa do governo que não economiza, grande parcela da população passa a entender que não há crescimento econômico, porque o dinheiro dos impostos está servindo para financiar programas sociais, como o Bolsa Família e o Minha Casa Minha Vida ou para manter a corrupção. As redes sociais, como o Facebook, que funcionam como termômetro dos acontecimentos produzidos nas mídias tradicionais, nos espaços políticos e jurídicos que se dão a conhecer pelas mesmas mídias, tornam-se cenários de grandes embates discursivos, sendo também o lugar onde os veículos de informação não convencionais ganham uma visibilidade, duvidosa para alguns e independente para outros. O que importa para este trabalho é que neste espaço, principalmente, os acontecimentos políticos e econômicos ganham contornos morais, autorizando os comportamentos intransigentes e a disseminação de ódio ao grupo de ideais de esquerda. Estes passam a ser os perigosos, aqueles que representam o risco não só para a economia e os rumos políticos do país, como também para o desejo de acúmulo de riquezas e de domínio social eterno dos mais abastados. A culpa é dos mais pobres e do PT, do expresidente Lula, nordestino e que saiu da classe baixa, como foi possível conferir nas manifestações da direita conservadora pela saída da Presidenta Dilma Rousseff e do Partido dos Trabalhadores do governo. A cena retratada na figura $1^{3}$ ilustra bem a disseminação de ódio e o desejo de extermínio daquele que é apontado como culpado.

Figura 1 - Manifestação em Fortaleza, em 13/06/2016, Cena 06 “Lula a pior praga do Brasil"

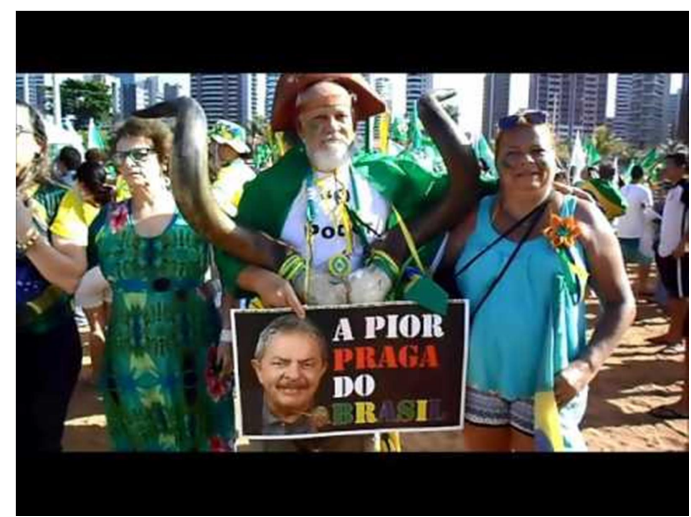

Fonte: https://www.youtube.com/watch?v=EFS1_jgJuks

\footnotetext{
${ }^{3}$ Disponível em: https://www.youtube.com/watch?v=EFS1_jgJuks
} 
EID\&A - Revista Eletrônica de Estudos Integrados em Discurso e Argumentação, Ilhéus, n. 16 esp. "Discurso e argumentação na política latino-americana, set.2018.

Os programas sociais passam ser vistos como um mau exemplo capaz de incentivar a produção de vagabundos e desocupados que sobreviverão à custa dos homens de bem, "trabalhadores", como no exemplo a seguir".

Figura 2

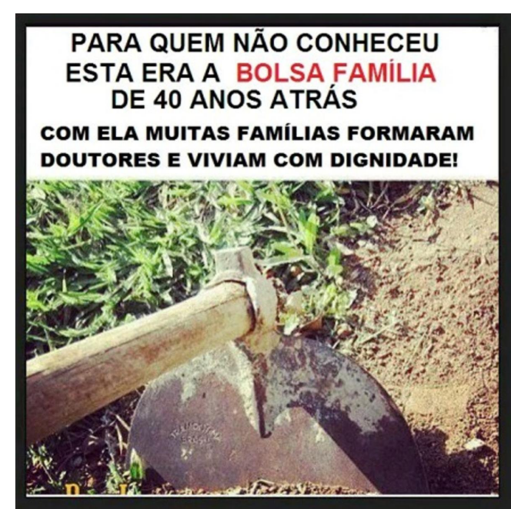

Fonte: http://therandomdelivers.blogspot.com/2013/06/bolsa-familia-e-canudo-dotoddynho.html

Com base em questionamentos infundados, como o que circulou nas redes sociais com a imagem anterior (Fig. 2), as agressões se tornam mais evidentes, quando aqueles que se reconhecem como "homens de bem" propõem o extermínio daqueles que eles consideram que "não têm moral" para viver entre os "bons", por depender do dinheiro do contribuinte "de bem" e não de seu próprio trabalho suado. A complexa situação geográfica, social e econômica da população brasileira é desconsiderada e todas as diferenças são apagadas em nome de verdades já cristalizadas em torno da confortável e surda crença na meritocracia no trabalho. Os valores neoliberais inculcados pela teoria do homo oeconomicus encontram o seu disfarce no acontecimento da corrupção para mascarar a crença no individualismo e na meritocracia, para justificar a indiferença às minorias que, conforme a referida teoria, deveriam investir em ações que fizessem de cada um, não um indivíduo de troca, um parceiro de outro indivíduo, mas um "empresário de si mesmo, sendo ele próprio seu capital, sendo para si mesmo seu produtor, sendo para si mesmo a fonte de sua renda" (FOUCAULT, 2008b, p. 311). A imagem seguinte acompanha um texto que tem como título "Juiz Sérgio Moro passa

4 Disponível em: http://therandomdelivers.blogspot.com/2013/06/bolsa-familia-e-canudo-dotoddynho.html 
EID\&A - Revista Eletrônica de Estudos Integrados em Discurso e Argumentação, Ilhéus, n. 16 esp. "Discurso e argumentação na política latino-americana, set.2018.

rasteira na malandragem de Lula" e que informa que o juiz trabalhou mesmo estando em férias para agilizar o processo contra Lula 5 .

Figura 3

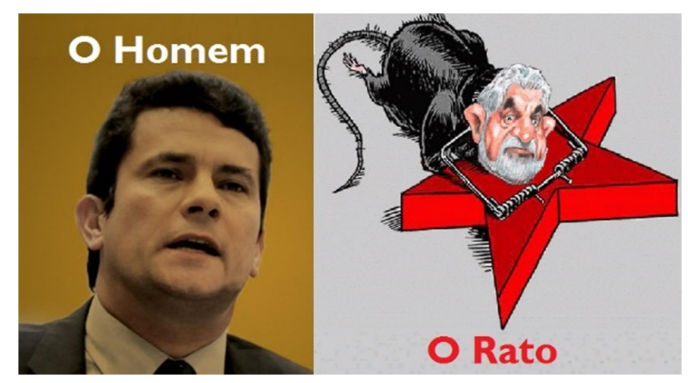

Fonte: http://vindodospampas.blogspot.com/2016/01/juiz-sergio-moro-passa-rasteirana.html

Todas essas imagens chegam ao grande público, quando reproduzidas nas redes sociais, e o desejo de extermínio dos culpados passa a ocupar as cenas do cotidiano, se voltando contra pessoas identificadas como de esquerda, políticos, representantes de grupos minoritários e artistas. Muitos destes, antes muito respeitados por sua história política no país, como o compositor, escritor e cantor Chico Buarque, sofrem agressões por aqueles que se julgam dignos, por sua história familiar tradicional, mas nem por isso honesta, para realizarem a limpeza da sociedade. A separação entre dois grupos se torna visível e ostentada: a esquerda e a direita; o social e o individual; o progressista e o conservador.

No Blog "Outras palavras", Raúl Zibechi, no texto intitulado América Latina: as bases sociais da nova direita ${ }^{6}$, analisa que

As classes médias são muito diferentes das dos anos 1960. Já não têm como referência as camadas de profissionais que se formaram em universidades públicas; que liam livros e continuavam estudando ao encerrar suas carreiras; que aspiravam a trabalhar por salários medianos em repartições estatais e se socializavam em espaços públicos onde confluíam com os setores populares. As novas classes médias têm como referência os mais ricos, aspiram a viver nos bairros privados, longe das classes populares e da trama urbana, são profundamente consumistas e desconfiam do pensamento livre. (ZIBECHI, in Blog Outras Palavras)

\footnotetext{
5 Disponível em: http://vindodospampas.blogspot.com/2016/01/juiz-sergio-moro-passa-rasteirana.html

${ }^{6}$ http://outraspalavras.net/mundo/america-latina/as-bases-sociais-da-nova-direita/
} 
EID\&A - Revista Eletrônica de Estudos Integrados em Discurso e Argumentação, Ilhéus, n. 16 esp. "Discurso e argumentação na política latino-americana, set.2018.

A nova direita no Brasil é constituída por segmentos que se homogeneízam em discursos que resgatam os valores mais conservadores da sociedade espalhados nas instituições políticas, jurídicas, religiosas e familiares, respaldadas e apoiadas pela grande mídia. O desejo de garantia econômica e de espaço político encontra a sua arma mais potente, a discriminação do diferente, do socialmente excluído, do economicamente explorado e daqueles que lutam para não cair no individualismo e defendem a igualdade de direitos.

A separação entre a esquerda inclusiva e a direita conservadora se deu também nas manifestações de rua convocadas por seus respectivos representantes. Manifestações que ocorrem em dias específicos para cada grupo, como forma de se evitar o confronto físico. As manifestações da direita têm sido marcadas pelo resgate do "nacionalismo", com a explicitação do amor à pátria por meio da indumentária verde-amarela, da solicitação, em cartazes, da volta do militarismo e da referência ao PT e seus defensores como comunistas que devem ser banidos. A imagem do outdoor ${ }^{7}$, a seguir, convida a população para a manifestação contra Dilma e o PT no dia 13/03/2016. As cores continuam como marca do patriotismo, e a expressão "Fora Comunistas" identifica o grupo locutor, os conservadores que querem manter seus privilégios e que não aceitam as políticas de inclusão e de diminuição das diferenças sociais. Mais interessante para este trabalho é que o grupo se coloca como aquele que pode conduzir a conduta da população, reunindo os bons para o trabalho de disseminação do mal.

Figura 4

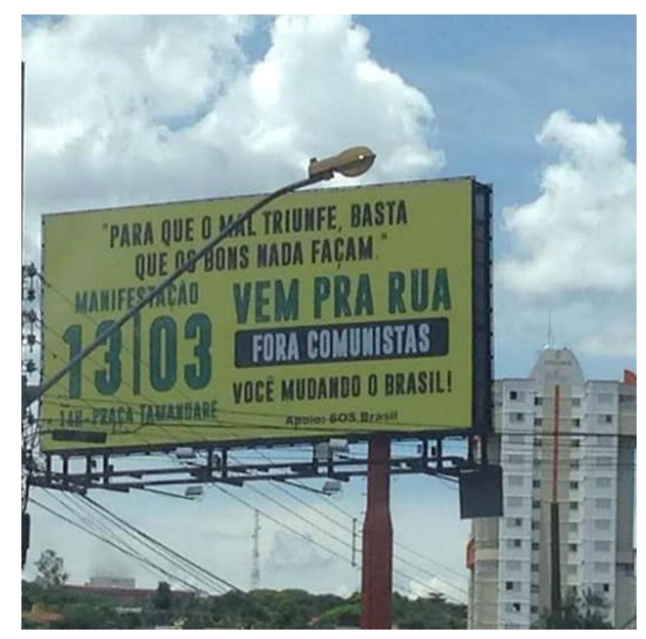

Fonte: Foto feita pela autora.

\footnotetext{
${ }^{7}$ Outdoor fotografado por nós em Goiânia no dia 3/4/2016.
} 
EID\&A - Revista Eletrônica de Estudos Integrados em Discurso e Argumentação, Ilhéus, n. 16 esp. "Discurso e argumentação na política latino-americana, set.2018.

\section{A condução da conduta dos homens e os jogos de verdade}

Ao se colocarem do lado da economia de mercado, que separa a classe de prestígio dos setores populares, os conservadores aliam a intransigência ao espírito salvacionista como forma de mostrar que se preocupa com o outro. Contudo, conforme Foucault (2008b, p. 353) em uma nota manuscrita, "um sujeito econômico é um sujeito que, no sentido estrito, procura em qualquer circunstância maximizar seu lucro, otimizar a relação ganho/perda; no sentido lato: aquele cuja conduta é influenciada pelos ganhos e perdas a ela associados". Assim, com atitudes que buscam a não anulação das tecnologias que visam influir no comportamento dos indivíduos, cada segmento recorre ao seu saber especializado para fazer a higienização necessária para a regulação da população e o funcionamento do dispositivo de segurança, nos termos de Foucault (2008a). A justiça e a mídia perseguem os suspeitos e apontam os culpados, focando naqueles que não pertencem aos partidos de direita. O texto Promiscuidade entre mídia e Judiciário ameaça a democracia ${ }^{8}$ de Felipe Bianchi traz notícia sobre debate ocorrido no dia 21/01/2016, no Barão de Itararé, em São Paulo. Um dos juristas participantes considera que "a mídia atua como braço do acusador, a defesa vira pura maquiagem e o julgamento, uma novela" e continua sua avaliação dizendo que:

[...] a fraude é algo que parece lícito, mas não é. E essa é a característica principal do fenômeno da "judicialização da política". Levando casos ao Judiciário, que monopoliza a interpretação das leis e da Constituição, atinge-se objetivos políticos - seja liquidar um adversário ou mesmo derrubar um governo. (BIANCHI, no site Centro de Estudos da Mídia Alternativa Barão de Itararé)

Essa relação entre política e Judiciário fica desvirtuada dada à cooptação desses espaços pela mídia, que toma partido em julgamentos e divulga apenas uma versão, ocultando a defesa. A parceria atua numa relação de poder em que a certeza sobre a verdade desvendada é estabelecida pelos argumentos de um discurso que serve de dados de comprovação para os outros discursos. Os saberes mobilizados para o fortalecimento da direita liberal no país passam por um processo de pedagogização, do qual saem filtrados por uma moral que infantiliza a população ao espetacularizar, na mídia, os bons exemplos dados por aqueles que devem conduzi-la pelo caminho do bem, e ao filtrar os enunciados, para facilitar o acesso ao sentido sugerido, por meio de

\footnotetext{
${ }^{8}$ Disponível em:

https://baraodeitarare.org.br/index.php?option=com_content\&view=article\&id=1179:promiscuidad e-entre-midia-e-judiciario-ameaca-a-democracia\&catid $=12 \&$ Itemid $=185$
} 
EID\&A - Revista Eletrônica de Estudos Integrados em Discurso e Argumentação, Ilhéus, n. 16 esp. "Discurso e argumentação na política latino-americana, set.2018.

metáforas, exemplos e ilustrações. Se cometeram crimes, isso é "conversa de gente grande", apenas sigam o que está sendo dito: "faça o que eu digo e não faça o que eu faço". A espetacularização da justiça e da política pela mídia tem se dado nesses termos. Aliás, Foucault (2008b, p. 344) chama a atenção para a definição e para o ponto de vista adotados pelos neoliberais na sua visão de crime: "é toda ação que faz um indivíduo correr o risco de ser condenado a uma pena [...] Eles [os neoliberais] se colocam do ponto de vista de quem comete ou vai cometer o crime." Não se trata mais do ponto de vista do ato.

O texto citado anteriormente traz ainda a fala de um ex-presidente da $\mathrm{OAB} / \mathrm{RJ}$, Wadih Damous, em que mostra as conexões confundindo o lugar discursivo da política e da justiça, quando espetacularizados na mídia: "A coação promovida no processo [Lava-Jato] é uma forma análoga à tortura”, sentencia. O problema, segundo ele, não é nem a judicialização da política, mas a politização da Justiça. "O que Sérgio Moro faz é político. É um agente político, senão partidário"9.

A acusação acima remete a uma atuação jurídica em que o sujeito de direito, obediente ao contrato, se concilia com o sujeito de interesse, o homo oeconomicus, obediente a seus interesses, conforme análise de Foucault (2008b) sobre o problema da identificação do objeto da análise econômica a toda conduta, que, finalizada nesse processo de identificação por meio de certos recursos, emerge como conduta racional. Nessa relação entre interesse e vontade jurídica, "o sujeito de interesse permanece, subsiste e continua enquanto há estrutura jurídica, enquanto há contrato" (FOUCAULT, 2008b, p. 374). Dessa forma, assistimos no Brasil dos últimos anos a um jogo político que coloca o debate em torno do problema de o sujeito de direito, que se constitui através do contrato, ser, no fundo, o sujeito do interesse, mas de um interesse depurado, que se tornou calculador e racionalizado. Nesse sentido, é importante, também, considerar com Foucault (2011) que o estudo dos mecanismos destinados a conduzir a conduta dos homens deve levar em conta o neoliberalismo, não só como teoria econômica e doutrina política, mas entendido como uma certa maneira de governar, como uma certa arte racional de governar, que exige a entrada nos jogos de verdade. As relações governo-verdade são definidas "em função de um certo real que seria o Estado ou que seria a sociedade: é a sociedade que seria objeto de saber, é a 
EID\&A - Revista Eletrônica de Estudos Integrados em Discurso e Argumentação, Ilhéus, n. 16 esp. "Discurso e argumentação na política latino-americana, set.2018.

sociedade que seria o lugar de processos espontâneos, sujeito de revolta, objeto e sujeito de fascinação pelo terror" (FOUCAULT, 2011, p. 59).

A condução da população, ou melhor, de sua conduta, é assumida por posições sujeitos autorizadas pelos saberes que a mídia torna aceitos como a verdade. A midiatização da política, da justiça e de grupos religiosos faz com que estes domínios discursivos adotem também o seu formato de argumentação: precipitar o acontecimento mesmo antes de o fato ocorrer. É a lei da concorrência, do pioneirismo, que marca a ideia de inovação que, para os neoliberais, é a renda do capital humano, isto é, o conjunto dos investimentos que foram feitos no nível do próprio homem (FOUCAULT, 2008b). E funciona, pois a força do dito faz um estrago tal que, mesmo depois de desmentido, a sua força continua irradiando sentidos para novos acontecimentos. Nesse jogo entre interesse e vontade jurídica, no trabalho de filtragem do tribunal econômico, notícias falsas, incompletas e deslocadas de contexto têm ganhado espaço na mídia impressa e digital, principalmente com a popularização das redes sociais, fazendo com que certos acontecimentos criados emerjam como definidores dos rumos de outros acontecimentos que já estavam delineados. É interessante refletir sobre o cálculo feito sobre o sentido daquilo que é inventado, sobre sua eficiência nos rumos de outros acontecimentos; um cálculo que considera os valores morais que constituem as ações e o dizer da sociedade e que sustentam e produzem as suas verdades. A prática de produção de notícias sem comprovação tem sido tão utilizada nos últimos anos que ganhou a entrada em dicionário com um termo novo para defini-la. Trata-se do termo Pós-Verdade, como pode ser conferido na matéria abaixo ${ }^{10}$.

Anualmente a Oxford Dictionaries, departamento da universidade de Oxford responsável pela elaboração de dicionários, elege uma palavra para a língua inglesa. A de 2016 é "pós-verdade" ("post-truth"). [...] Além de eleger o termo, a instituição definiu o que é a "pós-verdade": um substantivo "que se relaciona ou denota circunstâncias nas quais fatos objetivos têm menos influência em moldar a opinião pública do que apelos à emoção e a crenças pessoais”. "“Pós-verdade' deixou de ser um termo periférico para se tornar central no comentário político, agora frequentemente usado por grandes publicações sem a necessidade de esclarecimento ou definição em suas manchetes", escreve a entidade no texto no qual apresenta a palavra escolhida.

\footnotetext{
${ }^{10}$ Disponível em: https://www.nexojornal.com.br/expresso/2016/11/16/O-que-\%C3\%A9-

\%E2\%80\%98p\%C3\%B3s-verdade\%E2\%80\%99-a-palavra-do-ano-segundo-a-Universidade-de-Oxford
} 
EID\&A - Revista Eletrônica de Estudos Integrados em Discurso e Argumentação, Ilhéus, n. 16 esp. "Discurso e argumentação na política latino-americana, set.2018.

No curto trecho da matéria, chama a atenção a referência "à influência em moldar a opinião pública", indicando que nem tudo poder ser dito para alcançar o objetivo desejado e que a escolha do que vai ser dito é definida pela rede de discursos que, pelos saberes e pelas relações de poder, reforça a verdade aceita pela sociedade e produz os acontecimentos que apelam "à emoção e a crenças pessoais" já construídas.

Dentre os vários casos de uso da Pós-Verdade no cenário político brasileiro, como exemplo, tomamos uma notícia de 17 de dezembro de 2015, publicada no site do Jornal do Estado de São Paulo e intitulada "Dilma lança site para rebater 'boatos' sobre governo" - Página lista 13 'notícias' que circulam na internet e sobre as quais o governo afirma serem inverídicas" ${ }^{\text {"11 }}$. No lead que segue o título, a dúvida sobre ser ou não ser boato é sustentada pelo termo "notícias" entre aspas, preferido no lugar de boatos, e pela declaração de que "o governo afirma serem inverídicas", o que coloca a palavra do governo, já, neste momento, sem credibilidade, contra a palavra dos usuários da internet, que repetem as notícias lançadas por alguém ou por uma instituição não identificados. Na notícia, há a informação de que:

A nova página do Palácio do Planalto também carimba como boato que o governo vai confiscar a poupança dos brasileiros, que há uma "caixa-preta" no BNDES e que, com as mudanças na Previdência, o brasileiro só poderá se aposentar aos 95 anos. O site rebate ainda informações de que há espiões cubanos no Mais Médicos, que o governo está criando um exército de 20 mil haitianos e que o País está prestes a se tornar uma ditadura comunista.

Entre as explicações mais inusitadas está a de que a presidente não desfilou ao som da música "Beijinho no ombro" no dia 7 de setembro. "Na verdade, isso não ocorreu e trata-se somente de uma brincadeira de uma página de humor em uma rede social", diz o texto. Didático, o site tenta rebater com argumentos versões que circulam na internet e pede que o internauta use a ferramenta para verificar o que é verdade ou não sobre o governo. "Não compartilhe mentiras. $\mathrm{Na}$ internet as coisas fogem ao controle", diz a página inicial. (PERON, In Estadão, 17/12/2015)

A escolha dos boatos que devem circular vai ao encontro de verdades que constituíram historicamente os preconceitos de brasileiros, que dispensam o estudo mais aprofundado dos temas, tornando suas verdades irrefutáveis e definitivas, em relação à Cuba e ao comunismo, por exemplo. Até a sátira de uma página de humor, colocando a presidenta numa situação cômica, serve para construir uma verdade para ser descartada pelos valores

\footnotetext{
${ }^{11}$ http://politica.estadao.com.br/noticias/geral,dilma-lanca-site-para-rebater-boatos-sobregoverno, 10000005158
} 
EID\&A - Revista Eletrônica de Estudos Integrados em Discurso e Argumentação, Ilhéus, n. 16 esp. "Discurso e argumentação na política latino-americana, set.2018.

conservadores da sociedade e para produzir a subjetividade da pessoa da presidenta. Os boatos apelam para as crenças, para as emoções, provocando a sensação de que está tudo fora do lugar desejado, de que a desordem está tomando conta do país.

A insegurança e o medo, fenômenos produtivos do dispositivo de segurança, constroem também os culpados e os que devem ser excluídos para a garantia de segurança. Instaura um Estado de Exceção, como analisado por Agamben (2013), em que medidas intransigentes de disseminação do ódio a alguns grupos ditos perigosos e de propostas fascistas são justificadas e apoiadas por questões de segurança. É a condução das condutas pela repulsa a certas crenças religiosas, às homossexualidades, aos feminismos, a negros $\mathrm{e}$ índios; é a orientação aos "homens de bem" que, por isso, agridem, torturam e matam seus alvos de ódio.

Numa sessão da Assembleia Legislativa de Goiás em 2014, o Deputado Túlio Isaac, em seu discurso, disponível no Youtube ${ }^{12}$, além de agredir o colega da Comissão de Direitos Humanos, evocando seu nome e chamando os Direitos Humanos de "direitos dos manos", destila seu ódio sobre os menores infratores, declarando que "bandido bom é bandido morto" e incentiva os policiais a matarem os bandidos, a "meter bala na cara do bandido" e pede para "deixar a segurança pública trabalhar, sem a intervenção dos direitos humanos, ou direitos dos manos".

Como forma de garantir a liberdade, também produtiva para o neoliberalismo, a mídia, muitas vezes, não atua de forma explícita na política, na justiça, ou nas frentes em que conflitos religiosos e de preconceitos, que envolvam autoritarismo de poder, colocam em risco os direitos e a dignidade de cidadãos, mas divulga pesquisas, como a seguinte, que traz como título: "Pesquisadores apontam elo entre a crença em Deus e honestidade", publicada no dia 11 de fevereiro de 2016 na Folha de São Paulo ${ }^{13}$. A matéria apresenta a pesquisa em que, por meio de joguinhos, os pesquisadores relacionam a crença em Deus com o comportamento demonstrado com os adversários de jogo. A conclusão é a seguinte:

\footnotetext{
${ }^{12}$ Disponível em: https://www.youtube.com/watch?v=YEaiBkXy3vY

13 Disponível em: http://www1.folha.uol.com.br/ciencia/2016/02/1738513-pesquisadores-apontamelo-entre-a-crenca-em-deus-e-honestidade.shtml
} 
EID\&A - Revista Eletrônica de Estudos Integrados em Discurso e Argumentação, Ilhéus, n. 16 esp. "Discurso e argumentação na política latino-americana, set.2018.

[...] se o jogador fosse honesto, em média metade do dinheiro iria para cada cofrinho (15 moedas para cada lado, das 30 disponíveis para cada bateria). Os resultados? Entre as pessoas que não acreditavam no potencial de Deus ou dos deuses de vigiar e punir, parece ter havido ligeira malandragem: só 13 moedas iam parar no cofrinho das pessoas desconhecidas, em média.

A diferença no resultado não convence o leitor, mas a manchete já produz o efeito esperado e a possibilidade de que aquele dito pode ser dito. A veiculação da matéria em um momento em que o Congresso Nacional é ocupado por uma grande bancada de representantes dos evangélicos, sendo esses os defensores das políticas mais retrógradas para controle das condutas dos brasileiros, a matéria se faz como mais um argumento para mostrar que a verdade está do lado das igrejas.

\section{Considerações finais}

Como forma de problematizar a relação entre poder/verdade e a condução da conduta dos indivíduos no jogo político brasileiro, iniciamos este texto com a hipótese de que o exercício argumentativo se dá na tensão produzida nesses jogos estratégicos e na emergência do acontecimento discursivo. A descrição dos acontecimentos que produzem as práticas políticas na atualidade já requer que adentremos o campo de outras práticas para a compreensão do jogo argumentativo que funciona em rede de conexões.

A análise dos enunciados recortados que envolvem os discursos político, econômico, jurídico, midiático e religioso permitiu demonstrar a espetacularização dos eventos que possam justificar a queda definitiva da esquerda no Brasil, produzindo uma trama encenada por heróis (direita conservadora, justiça, mídia, igreja) e bandidos (a esquerda e os incluídos) e criando um efeito não da verdade, mas da busca da verdade que depende de um condutor de valores conservadores.

O giro à esquerda no Brasil, dentro do domínio do neoliberalismo e dos dispositivos de segurança, significou, para a direita, a possibilidade, explorada pela mídia, de instauração da insegurança e do medo, desencadeados, principalmente, pela política de inclusão, provocando a busca de refúgio nos modelos reacionários.

Nesse jogo de relações de poder e saber não só a mídia, a direita conservadora, o judiciário disfarçam sua natureza de vilões na condução da conduta da população, já que produzem acontecimentos para forçar as 
EID\&A - Revista Eletrônica de Estudos Integrados em Discurso e Argumentação, Ilhéus, n. 16 esp. "Discurso e argumentação na política latino-americana, set.2018.

manifestações populares nas ruas, mas também a própria população tem seus vilões disfarçados de heróis, despistando, pela luta por justiça e honestidade, os seus interesses individualistas e seu asco ao diferente. Há momentos, principalmente, nos fatos de economia, em que os bandidos nem disfarçam seus enunciados e deixam explícita a sua recusa às políticas de inclusão em favor do zelo à saúde do mercado financeiro. Poucas pessoas da população sabem sobre mercado financeiro e, portanto, não há necessidade de disfarce, pois, mesmo assim, os condutores da economia serão vistos como heróis. Como bem mostra Foucault (2011, p. 56-57), a arte de governar liberal está ligada à descoberta de uma verdade e

[...] isso implica a constituição de um saber especializado, a formação de uma categoria de indivíduos também especializados no conhecimento dessa verdade. E essa especialização constitui um domínio que não é exatamente próprio da política, e que define muito mais um conjunto de coisas e de relações que deverão se impor à política. [...] o inverso: o fato de um certo número de indivíduos apresentarem-se como especialistas da verdade a ser imposta à política é porque, no fundo, eles encobriram qualquer coisa. [...] é porque sabem e na medida em que sabem, na medida em que a evidência disso que se passa é efetivamente consciente a todo mundo, é nessa medida que as coisas não se modificam. (FOUCAULT, 2011, p.56-57)

Foucault (2008b) demonstra que a racionalidade econômica é rodeada por e fundada sobre a incognoscibilidade da totalidade do processo, sendo o mundo econômico, por natureza, opaco, obscuro, e a cegueira, necessária aos agentes econômicos, visto que o bem coletivo não deve ser visado, e o governo não deve criar obstáculos aos interesses dos indivíduos, cada um considerado como capital humano, o empresário de si mesmo, renda de sua própria competência-máquina, produtor de sua própria satisfação. A condução da conduta, nesse sentido, define os heróis, bem construídos economicamente, e os vilões, aqueles que produzem a desordem, ao não fazerem o investimento em seu próprio capital humano. Questões sociais, culturais, psicológicas são anuladas, nesse sentido, ou são assimiladas ao mercado econômico, justificando as atitudes de intolerância aos que não puderam produzir sua própria satisfação. A condução da conduta, numa luta em torno do saber/poder conta também com a obscuridade da linguagem na estruturação de enunciados que articulam o que a sociedade vai pensar, dizer e fazer como acontecimento histórico (DOSSE, 2013, p. 162) e permitindo a nomeação de práticas de falseamento da verdade, como testemunhamos no momento atual, sob o termo Pós-Verdade que autoriza a condução das 
EID\&A - Revista Eletrônica de Estudos Integrados em Discurso e Argumentação, Ilhéus, n. 16 esp. "Discurso e argumentação na política latino-americana, set.2018.

condutas dos indivíduos por uma verdade que assimila e conserva os valores morais de uma parcela da sociedade reacionária e conservadora.

\section{Referências}

AGAMBEN, Giorgio. Por uma teoria do poder destituinte. Atenas, Instituto Nicos Poulantzas e Juventude do SYRIZA, 16.11.2013. Entrevista Pública. Disponível em http://5dias.wordpress.com/2014/02/11/por-uma-teoria-do-poder-destituinte-degiorgio-agamben/. Acesso em: 01 mar.2014.

DOSSE, François. Renascimento do acontecimento: um desafio para o historiador: entre Esfinge e Fênix. São Paulo: Ed. Unesp, 2013.

FOUCAULT, Michel. A verdade e as formas jurídicas. Rio de Janeiro: Nau Ed., 1996.

. Segurança, território, população. São Paulo: Martins Fontes, 2008a.

. O Nascimento da Biopolítica. São Paulo: Martins Fontes, 2008b.

. Do governo dos vivos: Curso no Collège de France, 1979-1980. São Paulo: Centro de Cultura Social; Rio de Janeiro: Achiamé, 2011.

. Retornar à História. In: MOTTA, M. B. da (Org.). Foucault: Arqueologia das ciências e História dos sistemas de pensamento. Ditos e Escritos II. Rio de Janeiro: Forense Universitária, 2000.

LEMKE, Thania. Os riscos da segurança: liberalismo, biopolítica e medo. In: VACCARO, S. e AVELINO, N. (Org.). Governamentalidade/Segurança. São Paulo: Intermeios; Brasília: Capes, 2014.

Forma de citação sugerida:

SOUSA, Kátia Menezes de. Acontecimento e argumentação no jogo político: a verdade na construção de heróis e vilões. EID\&A - Revista Eletrônica de Estudos Integrados em Discurso e Argumentação, llhéus, n. 16 esp. "Discurso e argumentação na política latino-americana", p. 182-202, set.2018. 